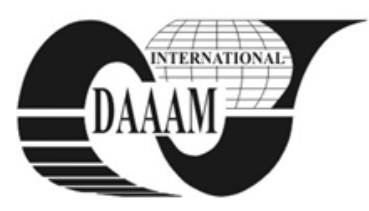

Annals of DAAAM for 2011 \& Proceedings of the 22nd International DAAAM Symposium, Volume 22, No. 1, ISSN 1726-9679 ISBN 978-3-901509-83-4, Editor B. Katalinic, Published by DAAAM International, Vienna, Austria, EU, 2011 Make Harmony between Technology and Nature, and Your Mind will Fly Free as a Bird Annals \& Proceedings of DAAAM International 2011

\title{
SYNERGISTIC OPTIMIZATION OF LOGISTICS PROCESSES VIA RFID TECHNOLOGY
}

\author{
JANAK, E[rik]
}

\begin{abstract}
Radio-frequency identification (RFID, for short) is without doubt one of the most discussed topics today. Accordingly, this article which can be divided into three main parts, deals with RFID issues, as well as with the possibility of synergistic optimization of business logistics processes via RFID. In the first part is briefly analyzed the current state of RFID use in Slovakia. Forasmuch as the greatest interest in RFID implementation is registered just in the automotive industry, in the second part are presented various problem areas, which are registered either in this branch or generally in all plants with rotating pallets. In the third, final part is further characterized the business logistics processes course, using RFID. Based on these problem areas, as well as their possible solutions through RFID, it may finally be noted that RFID is the key technology that allows the company the synergistic optimization of business logistics processes.
\end{abstract}

Key words: logistics processes, optimization, efficiency, RFID, synergy

\section{INTRODUCTION}

Radio-frequency identification (RFID, for short) is without doubt one of the most discussed topics today. In literature, as well as numerous articles, it is possible to encounter with many conflicting views of experts from different sectors. While one rejects RFID for its insecurity and high costs associated with its implementation, others see RFID as virtually the only one initial solution of the current situation. The fact is that many successfully implemented projects clearly testify in its favour. Accordingly, this article deals with the issue of radio-frequency identification, as well as the possibility of business logistics processes optimization through RFID technology.

\section{RFID IN SLOVAKIA}

RFID in Slovakia is not yet widely used. According to a survey of the use of information and communications technologies, which was conducted by the Statistical Office of the Slovak Republic, less than $5 \%$ of businesses with ten or more employees use the RFID technology.
$48.6 \%$ of enterprises use the RFID technology to access control or personal identification. Less than $17 \%$ of enterprises use this technology to label their products to protect against theft and the same percentage of companies to monitor stocks and flows in their supply chains (2009).

Greatest interest in the introduction of RFID technology is currently registered in the automotive industry and in the warehouse and production management.

The automotive industry in Slovakia is without doubt the most important branch of Slovak industry, which is characterized by high inflows of foreign investment, increasing support from the state and ultimately by using new technologies.

Automotive industry at the head of operations with rotating pallets represents an ideal field for RFID application in Slovakia.

\section{PROBLEM AREAS AND THEIR SOLUTIONS}

The first problem area is associated with already mentioned actual cycle of pallets, also known as reusable transport items or containers between suppliers and manufacturing plants. Problems in this area can be divided into five groups:

- lack of awareness of the availability of empty pallets, which causes further problems with the storage space,

- excess of pallets, which is caused by additional ordering of pallets and their unknown status on the stock. These pallets require more storage space and also generate the costs associated with their storage.

- wrong delivery of pallets - in this case, the pallets must be returned, which creates additional costs associated with their transport to the right place,

- thefts and losses of pallets, which generate the costs associated with buying or renting pallets,

- special transfers of pallets due to their unstable distribution, in order to cover the deficiency of pallets.

The second problem area that is shown in the figure 1 is associated with the actual movement of pallets or containers within the company.

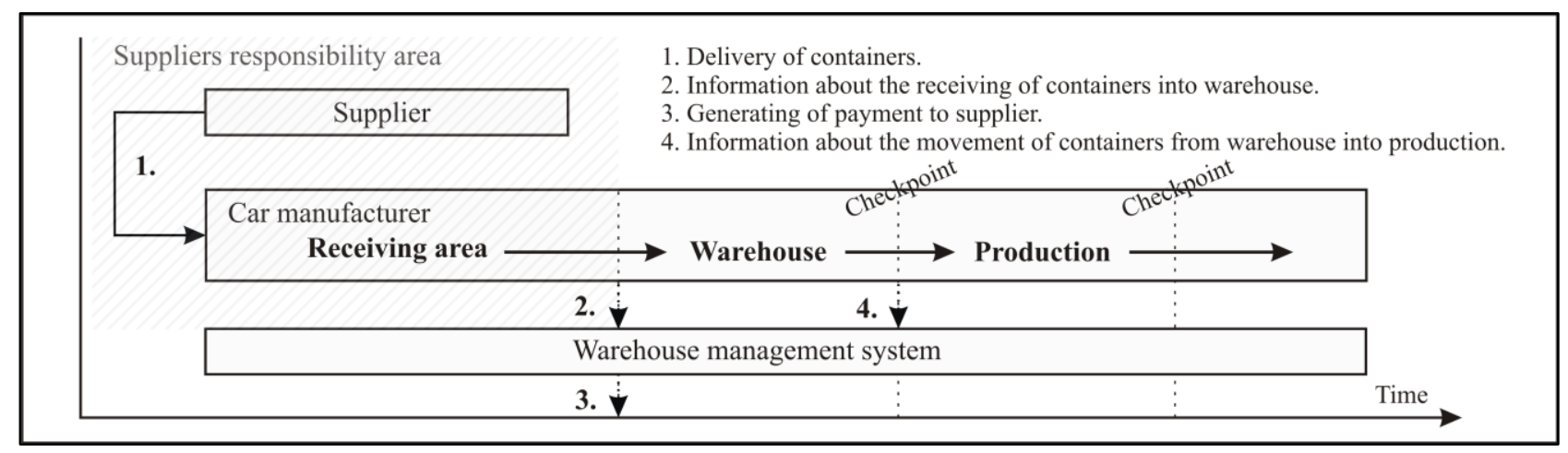

Fig. 1. Business logistics processes course without the support of RFID technology 


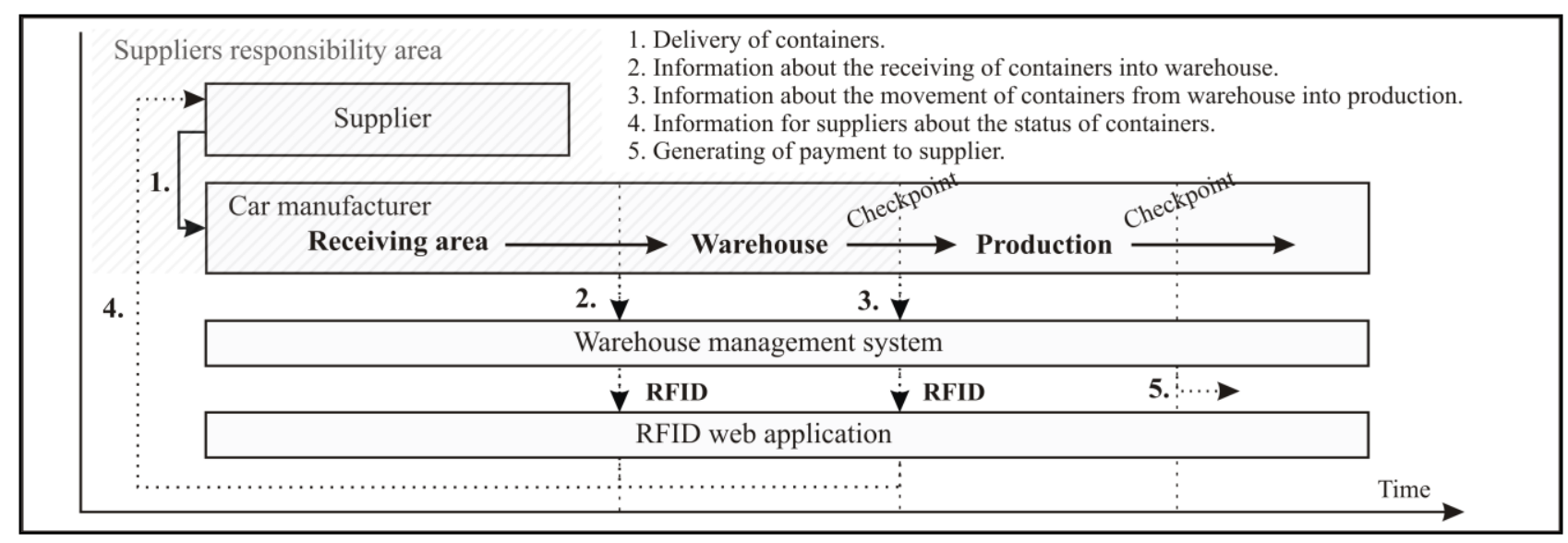

Fig. 2. Business logistics processes course with the support of RFID technology

This business logistics processes course without the support of RFID focuses on the problem area from shipping containers to the car manufacturer to their use in the production. In this case, it is talking about the special containers which are designed for robotic workstations, i.e. robots, which take the individual parts out of these pallets and assemble the body of them. These containers must be accurately calibrated, and therefore, they are subject to routine check. However, they are currently not being monitored in which cycle they occur. Thereby, there are cases when the uncalibrated container gets into the production process which will cause the shutdown of the robot, as well as the whole production line that is not able to operate them. This will trigger large losses in just a few minutes.

Another problem is that suppliers are unable to flexibly respond to the manufacturer's requirements. Suppliers deliver the individual parts based on orders generated from the total order by managing clerks. Suppliers deliver the required containers, but they do not know when the containers are depleted, because they actually have no access to the factory warehouse systems. Finally, it is necessary to mention the fact that some parts that are in a way damaged, get into production too. These parts are not used, but the payment has been already generated on their arrival to the warehouse which can create further problems associated with their complaints.

So, how should it work? The business logistics processes course supported by RFID technology can be illustrated by the figure 2. Suppliers deliver the parts on special pallets that are marked with RFID tags. On their arrival, the data from the individual labels are loaded into the information system, and the robot stores them according to their positions. After receiving the request from the production, they will be removed automatically. The robots select the individual parts and assemble the body of them. All this happens automatically without human intervention. RFID tags store the information about the car, including which parts are required and the sequence in which they go into the production.

The RFID technology also brings the solutions to the other, already mentioned problematic issues. On receipt of the containers into the warehouse and their movement from warehouse to production, the information is sent to the factory warehouse system. This information may be sent into the RFID web application that can be easily accessible to all suppliers. Suppliers are also informed immediately when the containers are used and can respond flexibly.

In addition, the company will obtain an overview of the actual position of the containers as well as their time of use. Based on this information, the payments to the suppliers can be generated. Therefore, the company will pay only for those containers that will be used. The current cycle of the container can be tracked through RFID tags. This will eliminate the danger that some uncalibrated container gets into production.
Given that the whole process of identifying of individual containers begins at the supplier, all of these problems associated with the cycle of containers between manufacturing plant and supplier can be removed and the storage space costs as well as the costs associated with their search and their transport to the right place significantly reduced.

In my research, I focused only on the automotive industry, but it is necessary to mention that all these problem areas are not related just to this branch of industry. As mentioned earlier, they are virtually related to all manufacturing operations with rotating pallets or containers. RFID technology would be also able to resolve the problem areas in other branches of industry.

Now the question becomes, how to implement RFID technology successfully and achieve the synergistic optimization of logistics processes? Therefore, the next step is the development of the implementation guideline that will be helpful in the RFID implementation process and will consider all the facts obtained by this research.

\section{CONCLUSION}

Based on the above examples of RFID technology use, various problem areas and ways of their solutions can be finally concluded that RFID technology is crucial in the process of synergistic optimization of business logistics processes. The introduction of RFID technology represents a single investment for the company that allows optimization and improvement of logistics processes' efficiency, virtually in all problem areas at once. The resulting effect is not only broader, but also more qualitative valuable than the effect that could be reached through the targeted optimization or improving the efficiency of logistics processes, particularly in all individual problem areas.

\section{REFERENCES}

Cibulka, V. (2010) Complex Approach to Goods Quality Improvement for the Company and the Customer, Hochschule Anhalt, ISBN 978-3-86011-035-5, Köthen.

Fleisch, E.; Mattern, F. (2005). Das Internet der Dinge Ubiquitous Computing und RFID in der Praxis Visionen, Technologien, Anwendungen, Handlungsanleitungen, Springer, ISBN 978-3-642-11460-1, Berlin, Heidelberg.

Klug, F. (2010). Logistikmanagement in der Automobilindustrie, Springer, ISBN: 978-3-642-05293-4, Berlin

Tamm, G.; Tribowski, Ch. (2010) RFID, Springer, ISBN 9783-642-11459-5, Berlin

*** (2009) http://technologie.etrend.sk/it-biznis/nastupcaciarovych-kodov-laka-aj-odradza-3.html Accessed on: 2011-06-20

*** (2009) http://portal.statistics.sk/showdoc.do?docid=19464, Accessed on: 2011-06-20 